\title{
Divergência genética em milho para baixo e alto nitrogênio visando à produção de óleo e proteína
}

\author{
Genetic divergence in maize under low and high nitrogen for \\ protein and oil production
}

'Universidade Federal do Tocantins (UFT), Rua Badejōs, Lote 7 Chăcaras 69/72, Zona Rural, CEP 77402-970, Gurupi, TO, Brasil

*autor correspondente \. farm.layannisd@gmail.com
Layanni Ferreira Sodré ${ }^{1 *}$, Weder Ferreira dos Santos ${ }^{1}$, Sérgio Donizeti Ascêncio' Joênes Mucci Peluzio ${ }^{1}$, Rafael Marcelino da Silva' ${ }^{1}$, Evandro Reina ${ }^{1}$
RESUMO: Considerando a importância econômica da cultura do milho (Zea mays L.) para o estado do Tocantins, Região Norte do Brasil, e a escassez de estudos sobre o efeito da adubação nitrogenada na divergência genética e na composição química dos grãos, foi realizado o presente trabalho. Neste sentido, foram efetuados dois ensaios de competição de genótipos de milho em Palmas (TO), na safra 2014/15, sendo um sob condições de alto $\mathrm{N}\left(150 \mathrm{~kg} \mathrm{ha}^{-1} \mathrm{de} \mathrm{N}\right)$ e outro sem $\mathrm{N}\left(0 \mathrm{~kg} \mathrm{ha}^{-1}\right.$ de $\left.\mathrm{N}\right)$ em cobertura no estádio V4, na forma de ureia. O delineamento experimental utilizado em cada ensaio foi de blocos ao acaso com três repetições e 18 tratamentos, sendo estes representados por 13 materiais de polinização aberta e cinco cultivares comerciais. As características estudadas foram os teores de óleo e proteína e os rendimentos de óleo, proteína e de grãos. A divergência genética, realizada para cada nível de adubação nitrogenada, foi obtida pelo método de otimização de Tocher. Os níveis contrastantes de nitrogênio resultaram em comportamento diferencial dos genótipos. As características que mais contribuíram para dissimilaridades genéticas foram rendimento de grãos, rendimento de proteínas e rendimento de óleo. Os genótipos P24-M1 × P37-3 e P36-16 × P37-3, ausência de cobertura de N, e P24-M1 × P29-M5, para alta dose de $\mathrm{N}$, são promissores para produção de proteína e óleo.

PALAVRAS-CHAVE: Adubação nitrogenada, diversidade, Zea mays.
ABSTRACT: Maize (Zea mays L.) is of great economic importance for the State of Tocantins, North Region, Brazil; however, the effect of nitrogen fertilization on genetic divergence and grain chemical composition is understudied. In this sense, we conducted two field experiments of maize genotypes competition at Palmas-TO, in the 2014/15 season. One field experiment was performed under high nitrogen $\left(150 \mathrm{~kg} \mathrm{ha}^{-1} \mathrm{~N}\right)$ and the other under low $N\left(0 \mathrm{~kg} \mathrm{ha}^{-1} \mathrm{~N}\right)$ in coverage. We used randomized blocks with three replications and 18 treatments (13 open-pollinated and five commercial varieties). The following traits were evaluated: protein and oil contents and; oil, protein and grain yield. The genetic diversity held for each level of nitrogen fertilization was obtained by Tocher optimization method. The contrasting nitrogen levels resulted in different behavior of genotypes. The following characteristics contributed the most to the genetic dissimilarity: grain yield, protein yield and oil yield. The genotype P24-M1 × P37-3 and P36-16 × P37-3, down N and $P 24-M 1 \times P 29-M 5$ to high $N$, are promising for the production of protein and oil.

KEYWORDS: Nutrition nitrogen, diversity, Zea mays.

\section{Introdução}

O milho é cultivado em todo o Brasil, tanto na agricultura familiar quanto nas grandes empresas agropecuárias (GALVÃO; MIRANDA, 2011), sendo um dos cereais mais cultivados e consumidos no mundo, tendo importância social, econômica, 
nutricional e agroindustrial (GALVÃO; MIRANDA, 2011; FANCELLI; DOURADO NETO, 2004).

No estado do Tocantins, a produtividade do milho é baixa, em razão das altas temperaturas, principalmente noturnas, do baixo nível tecnológico dos produtores e da insuficiência de sementes melhoradas ou de variedades adaptadas às condições de estresses abióticos (SANTOS et al., 2010; CANCELLIER et al., 2011).

$\mathrm{O}$ nitrogênio $(\mathrm{N})$, nutriente de alta demanda pela cultura do milho, exerce importante papel nos processos bioquímicos da planta, uma vez que é constituinte de proteínas, enzimas, coenzimas, ácidos nucleicos, fitocromos e clorofila (FARINELLI; LEMOS, 2012), que atuam no processo fotossintético e de absorção de nutrientes e água do solo, refletindo, em última instância, na produtividade de grãos (GALVÃO; MIRANDA, 2011).

A seleção de genótipos para ambientes pobres em $\mathrm{N} \mathrm{e} \mathrm{o}$ estudo da divergência genética têm sido objetos de estudos (CANCELLIER et al., 2011; HEINZ et al., 2012; SANTOS et al., 2014a, 2015a). Entretanto, são escassos os estudos sobre eficiência dos genótipos para a característica teor de óleo e proteína, rendimento de óleo, proteína e grãos, sob diferentes níveis de $\mathrm{N}$ no solo, no estado do Tocantins.

O conhecimento da divergência genética fornece parâmetros para a escolha de genitores que, ao serem cruzados, possibilitam mais efeito heterótico na progênie, aumentando as chances de obtenção de genótipos superiores em gerações segregantes (ROTILI et al., 2012).

A utilização de técnicas multivariadas para estimar a divergência tem se tornado comum e é empregada em trabalhos com a cultura do milho (DOTTO et al., 2010; COIMBRA et al., 2010; RIOS et al., 2010; SIMON et al., 2012; CARVALHO et al., 2011; ROTILI et al., 2012; SANTOS et al., 2014a, 2015a).

Dentre os procedimentos multivariados, o método de otimização de Tocher tem sido frequentemente utilizado na definição de estratégias de trabalhos de melhoramento envolvendo genótipos de milho (GUEDES et al., 2013).

Assim, o presente trabalho foi realizado com o intuito de estudar a divergência genética em genótipos de milho, na região central do estado do Tocantins, em dois ambientes distintos de fornecimento de nitrogênio, para a composição química dos grãos e rendimento, com vistas a identificar aqueles genótipos superiores para futuros cruzamentos.

\section{Material e Métodos}

Os ensaios de competição de genótipos de milho foram realizados no Centro Agrotecnológico da Universidade Federal do Tocantins (UFT), Campus de Palmas, com as seguintes coordenadas geográficas e de posição: altitude - $220 \mathrm{~m}$; latitude $-10^{\circ} 12^{\prime} \mathrm{S}$; longitude $-48^{\circ} 21^{\prime} \mathrm{W}$, em solo do tipo Latossolo Vermelho Amarelo distrófico, sendo um ensaio instalado sob condições de alto nitrogênio $\left(150 \mathrm{~kg} \mathrm{ha}^{-1} \mathrm{de} \mathrm{N}\right)$ e um sob ausência desse insumo $\left(0 \mathrm{~kg} \mathrm{ha}^{-1} \mathrm{de} \mathrm{N}\right)$. Os ensaios foram implantados em 10 de dezembro de 2014.

$\mathrm{O}$ delineamento experimental utilizado em cada ensaio foi de blocos ao acaso com 18 tratamentos e três repetições. Os tratamentos foram constituídos de 18 genótipos, sendo 13 de polinização aberta (P40-8, P36-19, P29-M12, P32-11, P36-16,
P28-2B, P37-3, P24-M1, P29-M5 UFT 1, UFT 5, UFT 7, UFT 4), oriundos de programas de melhoramento genético da Universidade Federal do Tocantins (UFT), e cinco comerciais, sendo quatro híbridos duplos (AG 1051, BR 205, BRAS 3010 e ORION) e um variedade (AL Bandeirante).

A parcela experimental utilizada foi composta de quatro linhas de cinco metros de comprimento, espaçadas com $0,90 \mathrm{~m}$ entre as linhas, deixando-se, após desbaste realizado aos 15 dias após o plantio, entre quatro e cinco plantas por metro linear, que correspondeu à densidade de 55.555 plantas por hectare.

$\mathrm{Na}$ colheita, foram utilizadas as duas linhas centrais de cada fileira, descartando-se $0,50 \mathrm{~m}$ das extremidades das fileiras.

Foram realizadas as operações de aração, gradagem e sulcamento. O plantio das sementes e a adubação no sulco de semeadura foram efetuados manualmente. A adubação de pré-plantio foi realizada utilizando $300 \mathrm{~kg} \mathrm{ha}^{-1}$ da formulação $5-25-15+0,5 \% \mathrm{Zn}$, para todos os ensaios, após prévia análise de solo, sendo os demais tratos culturais efetuados assim que se fizeram necessários conforme exigência da cultura.

As adubações nitrogenadas $(\mathrm{N})$ utilizadas em cobertura foram de 0 e $150 \mathrm{~kg} \mathrm{ha}^{-1}$, proporcionando totais de 15 e $165 \mathrm{~kg} \mathrm{ha}^{-1}$ de $\mathrm{N}$, para os ambientes de baixo e alto $\mathrm{N}$, respectivamente, sendo realizadas no estádio V4 (quatro folhas completamente abertas), tendo como fonte de $\mathrm{N}$ a ureia. As doses utilizadas para os ambientes de baixo e alto $\mathrm{N}$ correspondem à menor e à maior produtividade de grãos esperadas para a cultura do milho, conforme preconizado por Ribeiro et al. (1999).

Nas duas fileiras centrais, de cada parcela experimental, foram colhidas todas as espigas, quando as plantas atingiram o estádio R6 (maturidade fisiológica). Em seguida, as espigas foram trilhadas e os grãos de cada parcela foram acondicionados em um único saco de papel, o qual foi identificado por genótipo e transportado para o Laboratório de Pesquisa em Produtos Naturais (LPPN) da Universidade Federal do Tocantins - Campus de Palmas.

No laboratório, de cada parcela, foram obtidas as seguintes características: 1) teor de óleo (\%), obtido após moagem dos grãos, pelo método de Soxhlet, segundo o Instituto Adolfo Lutz (2005); 2) teor de proteína (\%), obtido após moagem dos grãos, pelo método de Kjeldahl (ASSOCIATION..., 1995), para determinação do nitrogênio total com conversão para proteína bruta por meio do fator 6,25 (VILLEGAS et al., 1985); 3) rendimento de grãos (massa de grãos de cada parcela corrigida para $13 \%$ de umidade e transformada em $\mathrm{kg} \mathrm{ha}^{-1}$ ); 4) rendimento de óleo $\left(\mathrm{kg} \mathrm{ha}^{-1}\right)$, oriundo do produto do rendimento de grãos pelo teor de óleo; 5) rendimento de proteína $\left(\mathrm{kg} . \mathrm{ha}^{-1}\right)$, oriundo do produto do rendimento de grãos pelo teor de proteína.

Após serem tabulados, os dados foram submetidos ao teste de normalidade. Em seguida, foram realizadas análise de variância de cada ensaio (nível de adubação) e, posteriormente, análise conjunta seguindo o critério da homogeneidade dos quadrados médios residuais dos ensaios.

Como em estudos de divergência genética são selecionados os parentais com as maiores médias em relação às características que se deseja melhorar, objetivando, desse modo, a máxima concentração de alelos favoráveis, conforme os objetivos da seleção (CRUZ et al., 2011), foi realizado o teste de Scott e Knott (1974) $(P=0,05)$, utilizando a média geral de cada genótipo. 
Para cada ensaio, foi realizado o estudo da divergência genética, sendo utilizada a distância generalizada de Mahalanobis $\left(\mathrm{D}^{2}\right)$, que leva em consideração as correlações entre as características analisadas, por meio da matriz de covariâncias residuais como medida de dissimilaridade. Posteriormente, foi utilizado o método de agrupamento de otimização de Tocher (RAO, 1952), que identifica o par mais similar dentro da matriz de dissimilaridade, isto é, aquele com menor estimativa de distância.

Para quantificar a contribuição relativa das características avaliadas na divergência genética, foi utilizado o critério de Singh (1981).

As análises estatísticas foram realizadas utilizando o programa Computacional Genes, versão 2007 (CRUZ, 2007).

\section{Resultados e Discussão}

Na análise de variância conjunta (Tabela 1), pode ser observado o efeito significativo para os ensaios, a 5\% de significância, para todas as características. Para os genótipos e a interação genótipos x ensaios, não foi detectada significância apenas para o teor de óleo (TO).
A significância dos genótipos indica a existência de variabilidade genética e a interação genótipos x ensaios revela a importância de realizar estudos de dissimilaridade genética utilizando ensaios diferentes. Outros autores também observaram efeitos significativos entre genótipos de milho e interação com ambiente quanto ao rendimento de proteína (SANTOS et al., 2014a), teor de óleo (SANTOS et al., 2014b, 2015a) e rendimento de grãos (CANCELLIER et al., 2011).

Os coeficientes de variação (CV) (Tabela 1) indicam boa precisão na condução dos experimentos. Segundo classificação proposta por Pimentel-Gomes (2009), o CV é classificado como baixo quando inferior a $10 \%$.

Em relação ao rendimento de grãos (RG) (Tabela 1), seis genótipos apresentam-se no grupo de produtividades superiores (P24-M1, UFT-1, P29-M5, P37-3, ORION e AG 1051). No grupo com as menores médias, encontram-se três genótipos cujas médias variaram de $4.125 \mathrm{~kg} \mathrm{ha}^{-1}$ (AL BANDEIRANTE) a $3.857 \mathrm{~kg} \mathrm{ha}^{-1}(\mathrm{P} 36-19)$. O ensaio sob alto $\mathrm{N}$ apresentou média geral $23 \%$ superior ao ensaio sob baixo $\mathrm{N}$, com média de 5.611 e $4.563 \mathrm{~kg} \mathrm{ha}^{-1}$, respectivamente. Cancellier et al. (2011),

Tabela 1. Média geral das características, rendimentos de grãos (RG), teor de proteína (TP), rendimento de proteína (RP), teor de óleo (TO) e rendimento de óleo (RO), referentes aos 18 genótipos de milho avaliados na safra 2014/15.

\begin{tabular}{|c|c|c|c|c|c|}
\hline Genótipos & RG (kg ha $\left.{ }^{-1}\right)$ & TP (\%) & RP $\left(\mathrm{kg} \mathrm{ha}^{-1}\right)$ & TO (\%) & $\operatorname{RO}\left(\mathrm{kg} \mathrm{ha}^{-1}\right)$ \\
\hline P24-M1 & 5887 a & 10,8 a & $639 a$ & $4,05 \mathrm{a}$ & $238 a$ \\
\hline P28-2B & 5392 b & 9,0 e & $502 d$ & $3,98 \mathrm{a}$ & $215 \mathrm{~b}$ \\
\hline P29-M12 & $4556 \mathrm{c}$ & $9,7 \mathrm{c}$ & $441 \mathrm{e}$ & 3,95 a & $180 \mathrm{~d}$ \\
\hline P29-M5 & 5772 a & $9,4 \mathrm{~d}$ & $546 \mathrm{c}$ & 3,99 a & $230 a$ \\
\hline P32-11 & $5385 \mathrm{~b}$ & $8,3 \mathrm{f}$ & 451 e & 3,95 a & $213 \mathrm{c}$ \\
\hline P36-16 & $5267 \mathrm{~b}$ & 10,7 a & $566 \mathrm{~b}$ & 3,90 a & $205 c$ \\
\hline P36-19 & $3857 d$ & 8,9 e & $346 \mathrm{f}$ & 3,89 a & $150 \mathrm{e}$ \\
\hline P37-3 & 5748 a & $10,4 \mathrm{~b}$ & $596 \mathrm{~b}$ & 3,84 a & $221 \mathrm{~b}$ \\
\hline P40-8 & $4579 \mathrm{c}$ & $8,5 \mathrm{f}$ & $389 \mathrm{f}$ & 3,81 a & $175 \mathrm{~d}$ \\
\hline UFT 1 & 5824 a & $8,4 \mathrm{f}$ & $487 d$ & $4,01 \mathrm{a}$ & 234 a \\
\hline UFT 4 & $4907 \mathrm{c}$ & $8,4 \mathrm{f}$ & $419 \mathrm{e}$ & $4,01 \mathrm{a}$ & $196 \mathrm{c}$ \\
\hline UFT 5 & $4888 \mathrm{c}$ & $7,5 \mathrm{~g}$ & $366 \mathrm{f}$ & $3,99 \mathrm{a}$ & $195 \mathrm{c}$ \\
\hline UFT 7 & $5226 \mathrm{~b}$ & 8,8 e & 459 e & 3,95 a & $206 \mathrm{c}$ \\
\hline AG 1051 & 5581 a & 9,0 e & $513 d$ & 3,93 a & $221 \mathrm{~b}$ \\
\hline AL BANDEIRANTE & $4125 d$ & $8,7 \mathrm{e}$ & $365 \mathrm{f}$ & 3,85 a & $159 \mathrm{e}$ \\
\hline BR 205 & $4077 d$ & $8,4 \mathrm{f}$ & $346 \mathrm{f}$ & $4,06 \mathrm{a}$ & $166 \mathrm{e}$ \\
\hline BRAS 3010 & $4905 \mathrm{c}$ & $8,8 \mathrm{e}$ & $433 \mathrm{e}$ & $3,67 \mathrm{a}$ & $180 \mathrm{~d}$ \\
\hline ORION & 5592 a & $9,3 \mathrm{~d}$ & $525 \mathrm{c}$ & $3,90 \mathrm{a}$ & $218 \mathrm{~b}$ \\
\hline \multicolumn{6}{|c|}{ Nitrogênio em cobertura $\left(\mathrm{kg} \mathrm{ha}^{-1}\right)$} \\
\hline $\mathbf{0}$ & $4563 \mathrm{~b}$ & $9,3 \mathrm{~b}$ & $380 \mathrm{~b}$ & 3,92 a & $179 \mathrm{~b}$ \\
\hline 150 & 5611 a & 9,8 a & 553 a & 3,94 a & 221 a \\
\hline Genótipo & * & $*$ & $*$ & ns & $*$ \\
\hline Ensaios & $*$ & $*$ & $*$ & $*$ & * \\
\hline Interação & * & $*$ & $*$ & ns & * \\
\hline Média & 5087 & 9,5 & 466 & 3,93 & 200 \\
\hline CV $(\%)$ & 6,5 & 3,5 & 6,8 & 4,3 & 7,3 \\
\hline
\end{tabular}

Médias seguidas pela mesma letra minúscula nas colunas pertencem a um mesmo grupo, de acordo com o critério de agrupamento de Scott e Knott (1974), a $5 \%$ de significância. * $\mathrm{e}^{\text {ns: }}$ : significativo e não significativo pelo teste $\mathrm{F}$ a $5 \%$ de significância. 
ao avaliarem genótipos de milho, observaram $23,6 \%$ de aumento de produtividade no ambiente de alto $\mathrm{N}$.

Os teores de proteína (Tabela 1) variaram de 7,5\% (UFT-5) a 10,8\% (P24-M1), sendo os genótipos P24-M1 $(10,8 \%)$ e P36-16 (10,7\%) aqueles com as maiores médias, seguidos por P37-3 (10,4\%). O menor conteúdo proteico foi UFT 5 $(7,5 \%)$. Esses valores médios se assemelham aos encontrados por Castro et al. (2009) com $8,05 \%$ e 9,21\% no grão de milho no estado de Goiás.

Os rendimentos de proteína (Tabela 1) variaram de $380 \mathrm{~kg} \mathrm{ha}^{-1}$ para $\mathrm{BN}$ e $553 \mathrm{~kg} \mathrm{ha}^{-1}$ para AN, com média geral de $466 \mathrm{~kg} \mathrm{ha}^{-1}$, sendo os maiores valores de $639 \mathrm{~kg} \mathrm{ha}^{-1}, 596 \mathrm{~kg} \mathrm{ha}^{-1}$ e $566 \mathrm{~kg} \mathrm{ha}^{-1}$, respectivamente, para os genótipos P24-M1, P37-3 e P36-16. O menor rendimento foi de $346 \mathrm{~kg} \mathrm{ha}^{-1}$ para P36-19 e BR 205. Santos et al. (2014b) encontraram rendimentos de proteína entre 619 e $340 \mathrm{~kg} \mathrm{ha}^{-1}$, em dez populações de milho, sob alto e baixo nitrogênio no estado do Tocantins.

Os teores de óleo (Tabela 1) variaram de 3,67\% (BRAS 3010) a 4,06\% (BR 205) (Tabela 1). Duarte et al. (2008), ao trabalharem com híbridos, encontraram a variação de $3,8 \%$ a $6,0 \%$ no teor de óleo nos grãos. Santos et al. (2014a) verificaram teores de óleo de 3,9\% a 6,7\% em dez populações de milho para duas épocas de plantio no estado do Tocantins. Santos et al. (2015b), ao trabalharem com 12 genótipos, em ensaios de alto, médio e baixo $\mathrm{N}$, em duas épocas de plantio, verificaram teores de óleo variando de $3,5 \%$ a $6,6 \%$, estando dentro da faixa encontrada na literatura.

Para a característica rendimento de óleo (RO) (Tabela 1), foram formados cinco grupos de médias, tendo o grupo com a maior média sido composto de P24-M1 (238 kg ha-1), P29-M5 (230 kg ha-1) e UFT-1 (234 kg ha-1). O grupo com a menor média foi P36-19 (150 kg ha-1), AL BANDEIRANTE (159 $\left.\mathrm{kg} \mathrm{ha}^{-1}\right)$ e BR 205 (166 kg ha-1). Santos et al. (2015a) encontraram rendimentos de óleo entre 288 e $164 \mathrm{~kg} \mathrm{ha}^{-1}$, em dez populações sob quatro experimentos de milho no município de Palmas, no estado do Tocantins.

As medidas de dissimilaridade genética, estimadas a partir da distância de Mahalanobis (Tabela 2), apresentaram elevada magnitude tanto para alto nitrogênio $(0,4$ a 132,7$)$ quanto para baixo nitrogênio $(0,9$ a 328,7$)$, e sugerem presença de variabilidade genética entre os genótipos avaliados.

Sob alto N (Tabela 2), a combinação P24-M1 e UFT 5 foi a mais divergente $\left(D^{2}=132,7\right)$, seguida pela combinação P29-M12 e P24-M1 ( $\left.\mathrm{D}^{2}=110,0\right)$. A menor distância foi observada pelos genótipos UFT 1 e UFT $4\left(\mathrm{D}^{2}=0,4\right)$, seguida pelo par P36-19 e AL BANDEIRANTE $\left(\mathrm{D}^{2}=0,6\right)$. Em baixo $\mathrm{N}$, o par UFT 4 e P36-16 foi o mais divergente $\left(\mathrm{D}^{2}=328,7\right)$, seguido pela combinação UFT 5 com P36-16 ( $\left.\mathrm{D}^{2}=322,5\right)$, UFT 5 com P24-M1 ( $\left.{ }^{2}=294,3\right)$ e UFT 1 com P24-M1 $\left(D^{2}=280,34\right)$. Já a menor distância na dose de BN foi obtida entre os genótipos UFT 4 e UFT $5\left(D^{2}=0,9\right)$, seguida pelo par UFT 7 e ORION $\left(\mathrm{D}^{2}=1,6\right)$.

A menor distância entre UFT 1 e UFT 4 (Tabela 2), em AN, e entre os genótipos UFT 4 e UFT 5, em BN, ocorreu, provavelmente, em razão de os genótipos dessas combinações serem oriundos de germoplasmas muito próximos. Em programas de melhoramento, deve-se evitar a hibridação entre genótipos com menor distância genética, ou seja, mais similares, uma vez que diminuiria o sucesso de híbridos com características desejáveis (SIMON et al., 2012).

A análise de agrupamento pelo método de otimização de Tocher proporcionou a formação de quatro grupos de genótipos, em ambos os níveis de $\mathrm{N}$, mas com diferentes constituições (Tabela 3).

Em baixo $\mathrm{N}$, foi formado um grande grupo constituído por 14 genótipos ( $77 \%$ dos genótipos), um grupo com dois genótipos (P36-16 e P24-M1) e dois grupos constituídos por apenas um genótipo (P37-3 e UFT-1, respectivamente). Sob alto $\mathrm{N}$, o maior grupo incluiu 12 genótipos (66\% dos genótipos), o segundo, quatro genótipos (P36-16, P37-3, P28-2B e P24-M1), e o terceiro e o quarto grupo, apenas um genótipo (AG 1051 e P29-M12, respectivamente). Segundo Cruz et al. (2011), grupos formados por apenas um genótipo apontam na direção de que este seja mais divergente em relação aos demais.

Ressalta-se que os genótipos que constituíram os pares mais divergentes (Tabela 2), com base na matriz de distâncias de Mahalanobis, foram alocados em grupos distintos pelo método de otimização de Tocher (Tabela 3). Os genótipos UFT 5, UFT 4 P32-11, BRAS 3010, P40-8, P36-19, ORION e P29-M5 foram alocados no mesmo grupo tanto na dose de BN quanto na dose AN, bem como os genótipos P36-16 e P24-M1.

As diferenças apresentadas quanto à composição dos grupos (Tabela 3 ) entre as doses de $\mathrm{N}$ pode ser explicada pela expressão ou não expressão dos alelos favoráveis presentes nos genótipos, que resultam em uma melhor absorção e aproveitamento do N no desenvolvimento da planta. Segundo Gallais e Hirel (2004), os alelos responsáveis para o controle genético da eficiência de $\mathrm{N}$ são expressos de acordo com o grau de disponibilidade deste.

Tais resultados estão em concordância com aqueles obtidos por Bueno et al. (2009) e Silva et al. (2015), que também verificaram comportamento diferencial de genótipos de milho quando submetidos a níveis contrastantes de nitrogênio.

As estimativas da contribuição relativa das cinco características avaliadas na dissimilaridade genética dos 18 genótipos estudados, para alto e baixo N, são apresentadas na Tabela 4. A característica que mais contribuiu para divergência na condição de BN foi a produtividade de grãos $(34,46)$, seguida pelo teor de proteína $(29,21)$. A característica que apresentou a menor contribuição foi teor de óleo $(0,20)$. Já na condição de AN, a que mais contribui foi rendimento de proteína $(43,36)$, seguida pela produtividade de grão $(35,29)$. Por outro lado, a característica que menos contribuiu foi teor de proteína $(0,43)$.

As características que mais contribuíram para explicar a divergência genética entre os genótipos, tanto na dose de AN quanto na dose de $\mathrm{BN}$, foram rendimento de grãos, rendimento de proteína e rendimento de óleo.

A análise de comparação de médias (Tabela 1), com o agrupamento estabelecido pelo método de Tocher (Tabela 3), permitiu identificar como potencialmente promissores os genótipos P24-M1 × P37-3 e P36-16 × P37-3, para baixo N, e P24-M1 × P29-M5, para alto N, para produção de energia. 
Tabela 2. Dissimilaridade entre 18 genótipos de milho em relação às características, com base na distância generalizada de Mahalanobis ( $\mathrm{D}^{2}$ ii $)$, sob alto $\mathrm{N}$ (acima da diagonal) e baixo N (abaixo da diagonal), na safra 2014/15 no Tocantins.

\begin{tabular}{|c|c|c|c|c|c|c|c|c|c|}
\hline GEN. & 1 & 2 & 3 & 4 & 5 & 6 & 7 & 8 & 9 \\
\hline 1 & & 2,6 & 1,6 & 2,3 & 24,5 & 47,5 & 53,0 & 12,92 & 15,3 \\
\hline 2 & 21,7 & & 4,3 & 0,6 & 24,5 & 32,5 & 59,6 & $\mathbf{9 , 5 1}$ & 19,1 \\
\hline 3 & 12,7 & 24,6 & & 3,6 & 28,0 & 47,4 & 57,8 & 21,71 & 19,0 \\
\hline 4 & 8,4 & 7,9 & 10,2 & & 19,1 & 29,6 & 49,9 & 9,58 & 13,9 \\
\hline 5 & 25,0 & 57,5 & 58,6 & 52,6 & & 33,6 & 13,9 & 19,73 & 12,9 \\
\hline 6 & 11,4 & 24,3 & 34,9 & 24,6 & 7,2 & & 67,5 & 37,08 & 38,6 \\
\hline 7 & 8,8 & 11,2 & 25,4 & 13,4 & 18,3 & 2,6 & & 46,36 & 17,7 \\
\hline 8 & 6,4 & 42,9 & 27,4 & 28,6 & 13,3 & 10,9 & 15,3 & & 16,9 \\
\hline 9 & 8,9 & 51,0 & 24,5 & 29,9 & 25,5 & 23,2 & 29,5 & 5,07 & \\
\hline 10 & 179,5 & 145,3 & 229,4 & 187,8 & 109,4 & 105,5 & 114,4 & 177,36 & 223,9 \\
\hline 11 & $\mathbf{5 , 7}$ & 41,3 & 11,7 & 21,2 & 31,0 & 22,9 & 22,8 & 6,04 & 3,0 \\
\hline 12 & 69,3 & 107,5 & 112,2 & 105,3 & 15,4 & 33,6 & 52,1 & 51,01 & 74,6 \\
\hline 13 & 174,3 & 168,2 & 220,8 & 189,2 & 99,7 & 109,5 & 124,4 & 173,36 & 208,3 \\
\hline 14 & 38,3 & 72,1 & 76,5 & 67,1 & 3,4 & 15,1 & 28,7 & 27,05 & 38,7 \\
\hline 15 & 85,1 & 144,2 & 136,1 & 130,8 & 63,3 & 81,1 & 97,3 & 57,73 & 50,9 \\
\hline 16 & 25,9 & 78,8 & 26,0 & 44,6 & 66,4 & 60,4 & 60,1 & 25,96 & 10,7 \\
\hline 17 & 20,5 & 44,0 & 50,7 & 41,5 & 1,6 & 3,8 & 11,8 & 14,54 & 25,3 \\
\hline 18 & 29,5 & 81,0 & 24,5 & 46,4 & 71,4 & 64,8 & 63,9 & 31,27 & 14,1 \\
\hline GEN. & 10 & 11 & 12 & 13 & 14 & 15 & 16 & 17 & 18 \\
\hline 1 & 47,5 & 46,6 & 64,5 & 92,5 & 28,4 & 9,7 & 8,4 & 4,7 & 8,4 \\
\hline 2 & 43,5 & 49,3 & 57,6 & 94,9 & 29,1 & 9,0 & 17,5 & 6,8 & 8,6 \\
\hline 3 & 50,2 & 50,1 & 68,5 & 95,1 & 31,2 & 11,9 & 9,7 & 7,4 & 12,0 \\
\hline 4 & 37,6 & 41,9 & 52,0 & 87,3 & 23,1 & 5,4 & 16,1 & 3,8 & 5,3 \\
\hline 5 & 6,0 & 7,3 & 14,0 & 34,4 & 0,8 & 5,7 & 46,7 & 12,8 & 5,8 \\
\hline 6 & 39,2 & 60,7 & 45,2 & 110,0 & 38,5 & 24,6 & 76,1 & 34,2 & 28,4 \\
\hline 7 & 24,7 & 8,2 & 36,6 & 41,8 & 10,7 & 23,7 & 63,1 & 30,0 & 24,1 \\
\hline 8 & 37,3 & 40,1 & 47,4 & 85,1 & 24,6 & 10,9 & 30,2 & 10,2 & 8,1 \\
\hline 9 & 35,6 & 26,6 & 52,1 & 80,2 & 14,6 & 4,9 & 18,7 & 3,3 & 4,7 \\
\hline 10 & & 8,2 & 2,0 & 19,3 & 5,6 & 20,2 & 82,7 & 34,2 & 21,4 \\
\hline 11 & 223,7 & & 15,5 & 15,9 & 3,6 & 20,5 & 70,1 & 30,9 & 21,3 \\
\hline 12 & 78,0 & 79,5 & & 19,6 & 13,9 & 32,7 & 107,4 & 50,1 & 33,7 \\
\hline 13 & 28,8 & 210,2 & 55,2 & & 28,3 & 62,3 & 132,7 & 80,1 & 63,0 \\
\hline 14 & 98,6 & 46,7 & 10,3 & 76,2 & & 7,7 & 50,4 & 15,7 & 8,4 \\
\hline 15 & 274,0 & 75,8 & 119,1 & 280,3 & 74,8 & & 24,4 & 2,2 & 0,4 \\
\hline 16 & 322,5 & 9,8 & 130,1 & 294,3 & 84,7 & 81,5 & & 12,3 & 22,6 \\
\hline 17 & 102,0 & 29,6 & 20,1 & 92,7 & 3,9 & 70,3 & 66,1 & & 1,7 \\
\hline 18 & 328,7 & 11,8 & 135,0 & 295,2 & 88,6 & 91,8 & 0,9 & $\mathbf{7 0 , 0}$ & \\
\hline
\end{tabular}

GEN-Genótipo.1-P40-8; 2-P36-19; 3-BR 205; 4-AL BANDEIRANTE; 5-ORION; 6-P29-M12; 7-AG 1051; 8-BRAS 3010; 9-P32-11; 10-P36-16; 11-P28-2B; 12-P37-3; 13-P24-M1; 14-P29-M5; 15-UFT 1; 16-UFT 5; 17-UFT 7; 18-UFT 4.

Tabela 3. Agrupamento pelo método de Tocher, com base na dissimilaridade expressa pela distância generalizada de Mahalanobis de 18 genótipos de milho, para baixo nitrogênio e alto nitrogênio, na safra 2014/2015, em Palmas (TO).

\begin{tabular}{|c|c|c|c|c|}
\hline Grupos & $\begin{array}{l}\text { Baixo nitrogênio } \\
\text { (BN) }\end{array}$ & $\begin{array}{c}\text { Genótipos } \\
(\%)\end{array}$ & $\begin{array}{l}\text { Alto nitrogênio } \\
\text { (AN) }\end{array}$ & $\begin{array}{c}\text { Genótipos } \\
\text { (\%) }\end{array}$ \\
\hline $\mathbf{I}$ & $\begin{array}{l}\text { UFT 5, UFT 4, P28-2B, P32-11, BRAS 3010, } \\
\text { P40-8, BR 205, AL BANDEIRANTE, AG 1051, } \\
\text { P29-M12, UFT 7, ORION, P36-19, P29-M5 }\end{array}$ & 77 & $\begin{array}{l}\text { UFT1, UFT 4, UFT 5, UFT 7, P32-11, AL } \\
\text { BANDEIRANTE, P40-8, P36-19, BR 205, } \\
\text { BRAS 3010, ORION, P29-M5 }\end{array}$ & 66 \\
\hline II & P36-16 e P24-M1 & 11 & P36-16, P37-3, P28-2B е P24-M1 & 22 \\
\hline III & P37-3 & 6 & AG 1051 & 6 \\
\hline IV & UFT 1 & 6 & P29-M12 & 6 \\
\hline Total & & 100 & & 100 \\
\hline
\end{tabular}


Tabela 4. Contribuição relativa das cinco características para o processo de dissimilaridade genética dos 18 genótipos de milho.

\begin{tabular}{ccc}
\hline Característica & Baixo N & Alto N \\
\hline Rendimentos de grãos $\left(\mathrm{kg} \mathrm{ha}^{-1}\right)$ & 34,46 & 35,29 \\
Teor de proteína $(\%)$ & 29,21 & 0,43 \\
Rendimento de proteína $\left(\mathrm{kg} \mathrm{ha}^{-1}\right)$ & 23,06 & 43,36 \\
Teor de óleo $(\%)$ & 0,20 & 3,28 \\
Rendimento de óleo $\left(\mathrm{kg} \mathrm{ha}^{-1}\right)$ & 13,07 & 17,64 \\
TOTAL & 100 & 100 \\
\hline
\end{tabular}

\section{Conclusões}

Os níveis contrastantes de nitrogênio resultam em comportamento diferencial dos genótipos.

As características que mais contribuíram para dissimilaridades genéticas foram rendimento de grãos, rendimento de proteínas e rendimento de óleo.

Os genótipos P24-M1 × P37-3 e P36-16 × P37-3, para baixo $\mathrm{N}$, e P24-M1 × P29-M5, para alto $\mathrm{N}$, são promissores para produção de proteína e óleo.

\section{Referências}

ASSOCIATION OF OFFICIAL ANALYTICAL CHEMISTS - AOAC.

Vitamins and other nutrients. In: Official methods of analysis. 16. ed. Arlington: AOAC International, 1995. p. 58-61. cap. 45 .

BUENO, L. G. et al. Controle genético do teor proteico nos grãos e de caracteres agronômicos em milho cultivado com diferentes níveis de adubação nitrogenada. Pesquisa Agropecuária Brasileira, Brasília, v. 44, n. 6, p. 590-598, 2009.

CANCELLIER, L. L. et al. Eficiência no uso de nitrogênio e correlação fenotípica em populações tropicais de milho no Tocantins. Revista Ciência Agronômica, Fortaleza, v. 42, p. 139-148, 2011.

CARVALHO, E. V. et al. Desempenho agronômico e divergência genética na seleção de linhagens $\mathrm{S}_{5}$ de milho. Bioscience Journal, Uberlândia, v. 27, n. 5, p. 794-797, 2011.

CASTRO, M. V. L. et al. Rendimento industrial e composição química de milho de alta qualidade protéica em relação a híbridos comerciais. Pesquisa Agropecuária Tropical, Goiânia, v. 39, p. 233-242, 2009

COIMBRA, R. R. et al. Caracterização e divergência genética de populações de milho resgatadas do Sudeste de Minas Gerais. Revista Ciência Agronômica, Fortaleza, v. 41, n. 1, p. 159-166, 2010.

CRUZ, C. D. Programa Genes: aplicativo computacional em genética e estatística. Viçosa: UFV, 2007. 442 p.

CRUZ, C. D.; FERREIRA, F. M.; PESSONI, L. A. Biometria aplicada ao estudo da diversidade genética. Visconde do Rio Branco: Suprema, 2011. 620 p.

DOTTO, M. A. et al. Divergência genética entre cultivares comerciais de milho em baixas altitudes no Tocantins, safra 2007/2008. Revista Ciência Agronômica, Fortaleza, v. 41, p. 630-637, 2010.
DUARTE, A. P.; CARVAlHO, C. R. L.; CAVICHIOLI, J. C. Densidade, teor de óleo e produtividade de grãos em híbridos de milho. Bragantia, Campinas, v. 67, p. 759-767, 2008.

FANCELLI, A. L.; DOURADO-NETO, D. Produção de milho. 2. ed. Piracicaba, 2004. 360 p.

FARINELLI, R.; LEMOS, L. B. Nitrogênio em cobertura na cultura do milho em preparo convencional e plantio direto consolidados. Pesquisa Agropecuária Tropical, Goiânia, v. 42, n. 1, p. 63-70, 2012.

GALLAIS, A.; HIREL, B. An approach to the genetics of nitrogen use efficiency in maize. Journal of Experimental Botany, Oxford, v. 55, n. 396 , p. $295-306,2004$.

GALVÃO, J. C. C.; MIRANDA, G. V. Produção de milho em pequenas propriedades. Viçosa: CPT, 2011. $300 \mathrm{p}$

GUEDES, J. M. et al. Divergência genética entre cafeeiros do germoplasma Maragogipe. Bragantia, Campinas, v. 72, n. 2, p. 127-132, 2013.

HEINZ, R. et al. Seleção de progênies de meio-irmãos de milho para eficiência no uso de nitrogênio. Revista Ciência Agronômica, Fortaleza, v. 43, p. 731-739, 2012.

INSTITUTO ADOLFO LUTZ - IAL. Normas analíticas do Instituto Adolfo Lutz: métodos químicos e físicos para análise de alimentos. São Paulo: IAL, 2005. 317 p.

PIMENTEL-GOMES, F. Curso de estatística experimental. 15. ed. Piracicaba: FEALQ, 2009. 451 p.

RAO, C. R. Advanced statistical methodos in biometri cresearch New York: John Willey, 1952. 390 p.

RIBEIRO, A. C.; GUIMARÃES, P. T. G.; ALVAREZ, V. V. H. Recomendação para o uso de corretivos e fertilizantes em Minas Gerais: $5^{\text {a }}$ aproximação. Viçosa: UFV, 1999. 359 p.

RIOS, S. A. et al. Divergência genética entre genótipos de milho quanto ao teor de carotenóides nos grãos. Revista Brasileira de Milho e Sorgo, Sete Lagoas, v. 9, n. 3, p. 277-286, 2010.

ROTILI, E. A. et al. Divergência genética em genótipos de milho, no estado do Tocantins. Revista Ciência Agronômica, Fortaleza, v. 43, p. 516-521, 2012.

SANTOS, M. M. et al. Épocas de aplicação de nitrogênio em cobertura na cultura do milho em plantio direto, e alocação do nitrogênio $\left({ }^{15} \mathrm{~N}\right)$ na planta. Revista Brasileira de Ciência do Solo, Viçosa, v. 34, p. 1185-1194, 2010.

SANTOS, W. F. et al. Variabilidade genética e eficiência de uso do nitrogênio em populações de milho para teor de óleo. Revista de Ciências Agrárias, Belém, v. 57, p. 312-317, 2014a.

SANTOS, W. F. et al. Épocas de semeadura, doses de nitrogênio e rendimento de proteína em populações de milho. Revista Tecnologia \& Ciência Agropecuária, João Pessoa, v. 8, n. 4, p. 13-16, 2014b.

SANTOS, W. F. et al. Divergência genética e eficiência no uso do nitrogênio em populações de milho, visando à produção de óleo. Revista Tecnologia \& Ciência Agropecuária, João Pessoa, v. 9 , n. 4, p. 33-38, 2015a.

SANTOS, W. F.; AFFÉRRI, F. S.; PELUZIO, J. M. Eficiência ao uso do nitrogênio e biodiversidade em genótipos de milho para teor de óleo. Enciclopédia Biosfera, Goiânia, v. 11, n. 21, p. 2916-2925, 2015b. 
SCOTT, A. J.; KNOTT, M. A. Cluster analysis method for grouping means in the analysis of variance. Biometrics, Washington, v. 30 , p. 507-512, 1974.

SILVA, K. C. L. et al. Divergência genética de genótipos de milho com e sem adubação nitrogenada em cobertura. Revista Agro@ mbiente Online, Boa Vista, v. 9, n. 2, p. 102-110, 2015.

SIMON, G. A.; KAMADA, T.; MOITEIRO, M. Divergência genética em milho de primeira e segunda safra. Semina: Ciências Agrárias, Londrina, v. 33, n. 2, p. 449-458, 2012.
SINGH, D. The relative importance of characters affecting genetic divergence. Indian Journal of Genetics and Plant Breeding, New Delhi, v. 41, p. 237-245, 1981.

VILLEGAS, E.; ORTEGA, E.; BAUER, R. Métodos químicos usados em EI CIMMYT para determinar la calidad de proteína de lós cereales. México: Centro Internacional de Mejoramiento de Mays y Trigo, 1985. 34 p. 